\title{
Modelling of electricity savings in the Danish households sector: from the energy system to the end-user
}

\author{
Baldini, Mattia; Trivella, Alessio
}

Published in:

Energy Efficiency

Link to article, DOI:

10.1007/s12053-017-9516-5

Publication date:

2018

Document Version

Peer reviewed version

Link back to DTU Orbit

Citation (APA):

Baldini, M., \& Trivella, A. (2018). Modelling of electricity savings in the Danish households sector: from the energy system to the end-user. Energy Efficiency, 11(7), 1563-1581. https://doi.org/10.1007/s12053-017-9516-5

\section{General rights}

Copyright and moral rights for the publications made accessible in the public portal are retained by the authors and/or other copyright owners and it is a condition of accessing publications that users recognise and abide by the legal requirements associated with these rights.

- Users may download and print one copy of any publication from the public portal for the purpose of private study or research.

- You may not further distribute the material or use it for any profit-making activity or commercial gain

- You may freely distribute the URL identifying the publication in the public portal 


\title{
Modelling of electricity savings in the Danish households sector: from the energy system to the end-user
}

\author{
Mattia Baldini, Alessio Trivella \\ Department of Management Engineering, Technical University of Denmark \\ mbal@dtu, atri@dtu.dk
}

\begin{abstract}
In this paper we examine the value of investing in energy-efficient household appliances from both an energy system and end-user perspectives. We consider a set of appliance categories constituting the majority of the electricity consumption in the private household sector, and focus on the stock of products which need to be replaced. First, we look at the energy system and investigate whether investing in improved energy efficiency can compete with the cost of electricity supply from existing or new power plants. To assess the analysis, Balmorel, a linear optimization model for the heat and power sectors, has been extended in order to endogenously determine the best possible investments in more efficient home appliances. Second, we propose a method to relate the optimal energy system solution to the end-user choices by incorporating consumer behaviour and electricity price addition due to taxes. The model is non-exclusively tested on the Danish energy system under different scenarios. Computational experiments show that several energy efficiency measures in the household sector should be regarded as valuable investments (e.g. an efficient lighting system) while others would require some form of support to become profitable. The analysis quantifies energy and economic savings from the consumer side and reveals the impacts on the Danish power system and surrounding countries. Compared to a business-as-usual energy scenario, the end-user attains net economic savings in the range of 30-40 EUR per year, and the system can benefit of an annual electricity demand reduction of 140-150 GWh. The paper enriches the existing literature about energy efficiency modelling in households, contributing with novel models, methods, and findings related to the Danish case.
\end{abstract}




\section{Introduction}

In compliance with the recent international effort towards the climate change mitigation (European Commission 2010), Denmark has set its goals for the year 2020 and is working to fulfil the targets concerning renewable energy (RE) integration in the system and energy efficiency (EE) improvements. Compared to the 1990 levels, Denmark has reduced its greenhouse gas emissions by more than $30 \%$ and, according to the current policies and trends, the Danish Energy Agency forecasts that the reduction will reach almost $40 \%$ by 2020 (Breum 2015), thus exceeding the legally binding EU commitment of $34 \%$. Denmark can vaunt one of the highest contributions of renewables in any energy system worldwide (excluding hydro-power), with a 56\% contribution in 2014. In particular, in 2015, more than $40 \%$ of the Danish electricity demand was satisfied by wind energy, and this figure is expected to increase up to $50 \%$ by 2020 (Breum 2015). Besides the effort in integrating renewables in the energy system, the Danish government has set a number of targets for the further development of EE measures. According to the National 2020 Energy Efficiency Targets, Denmark is aiming to reduce the primary and final energy consumption by 12.6 and $7.2 \%$, respectively, compared to 2006 (Danish Energy Agency 2014).

Both RE and EE measures have been identified by the European Commission as the most suitable options to evolve the national energy systems towards greener configurations (European Commission 2012). Nevertheless, if not properly enforced, the simultaneous implementation of RE and EE can lead to suboptimal investment planning and missed cost-saving opportunities (Baldini and Klinge Jacobsen 2016). The challenge is to identify the optimal trade-off between EE levels and power system configurations while exploring future scenarios, i.e. understanding where to invest in order to obtain the most cost-effective energy system given a target on emissions reduction. Several studies, for instance, have shown that enhancing EE is likely the most costeffective way to reduce carbon emissions in the medium term (López-Peña et al. 2012, Enkvist et al. 2007).

The literature has then considered the modelling of EE in households along two main lines: the heat and electricity sectors. Available literature presents many examples from the Danish heating context, while EE literature from the electricity sector is lacking, whereby we broaden our perspective.

On the heat sector side, Zvingilaite (2013) models heat savings in the Danish building sector using a heat and power optimization model, showing that the attainable level 
of heat savings can reach up to $11 \%$ of the projected heat demand in 2025 . At the time of publication, the study represented the front-runner implementation of heat savings as endogenous investment variables in an energy system model, thus providing a first estimation of the cost-effective heat savings level from a socio-economic perspective. Several studies target environmental goals as $\mathrm{CO}_{2}$ emission reduction, stressing the need to identify the trade-off between heat savings and heat supply. Connolly et al. (2014) examine the joint role of district heating and heat savings to decarbonise the EU energy system, and conclude that coupling the two measures can help reducing primary energy supply and $\mathrm{CO}_{2}$ emissions at the lowest costs compared to other alternatives. Zvingilaite and Klinge Jacobsen (2015) investigate the trade-off between heat savings and heat generation technologies in the Danish energy system, focusing on the residential investment behaviour and including health costs. The study reveals that savings up to $24 \%$ of the heat demand can be achieved with an optimal configuration of investments in heat savings and heat generation technologies. Hansen et al. (2016) estimate the optimal heat savings investment levels within various European countries. This level is identified in investments aimed to reduce the projected heat demand of about 30-40\%, while supplying the remaining demand with sustainable heat technologies.

On the electricity side, the literature suggests that disaggregating the household electricity demand into different appliances is the starting point for modelling EE measures and the attitude of consumers towards them (Lefebvre and Desbiens 2002, Evora et al. 2011, Batih and Sorapipatana 2016). Rodríguez Fernández et al. (2015) propose the use of machine learning techniques to identify individual electrical devices in households based on power consumption, so that specific appliances can be targeted for efficiency improvement. Numerous authors then focused on the trade-off between electric energy savings in households and power supply with interesting examples, close to the direction of our work, in an Asian context. Parikh and Parikh (2016) examine the potential energy and emission savings from choosing energy-efficient home appliances in India. Based on the 5-star-rating EE promotion programme, the authors modelled the attitude of consumers (poor and rich) in adopting more efficient appliances. The results show that, given the awareness of consumers concerning the various options of efficient appliances, a demand and emission reduction from households exceeding 30\% can be reached in 2030. Batih and Sorapipatana (2016) analyse the electricity consumption of urban households and its saving potential in Indonesia. Similar to the Indian's case, the results illustrate how implementing specific EE improvements can lead to a reduction of $21 \%$ of both power demand and $\mathrm{CO}_{2}$ emissions from households by 2030 . Xie et al. (2016) prove that energy management strategies in the Chinese household 
sector should include investments in energy-efficient home appliances. The policy recommendation is thus in terms of subsidies driving customers to purchase a higher share of energy-labelled appliances. Mizobuchi and Takeuchi (2016) examine the influence of an increase in purchasing energy-efficient home appliances on the power system in Japan. The conclusions are in line with previous studies, showing that households with new energy-efficient appliances can save a large amount of electricity, but also that the rebound effect may cancel part of the savings out due to a more intense use of the appliance. Finally, a few studies consider the contribution of appliances to the household electricity use with a global scope, illustrating the huge potential of energy efficiency improvements in the global residential sector (Wada et al. 2012, Cabeza et al. 2014).

As indicated by the consistent amount of literature, in the residential sector lies a large potential for EE improvements. In Denmark, electricity consumption from private households exceeds $20 \%$ of the total load (Klinge Jacobsen and Juul 2015). This figure is also expected to increase in the next years due to the upcoming electrification of the household facilities, and should then be balanced with improvements in energy efficiency measures (Bartiaux and Gram-Hanssen 2005). The electricity consumption in the household sector is mainly related to the different home appliances. Therefore, if electricity savings could be targeted to the different appliance categories, then lower consumption profiles associated to the households could lead to savings for the system in terms of necessary power plants, capacity investments and emissions. Furthermore, the electricity savings may have different effects on the power system depending on the hourly consumption profile of the appliance category whose demand is reduced.

Using a bottom-up approach (Swan and Ugursal 2009), the analysis proposed in this paper will make use of hourly consumption profiles of home appliances determined in previous studies (Klinge Jacobsen and Juul 2015) to investigate the effect of EE improvements in the Danish energy system. In particular, the aim of this paper is threefold:

1. to evaluate from a system perspective whether it is worth to invest in more energyefficient appliances rather than install new power plants, and observe the effects on the energy mix;

2. to assess from an end-user perspective which energy-efficient appliance should be regarded as a profitable investment, taking into account the behavioural dimension of the consumer;

3. to compare the investment choices of the model according to the system and consumer perspectives. 
The paper enriches the existing literature about EE modelling in households, contributing with new models, methods, and findings related to the Danish case.

\section{Methodology}

\subsection{Overview of Balmorel}

Balmorel is a linear programming-based optimization model for the energy sector, originally developed in 2001 to analyse the Baltic system (Balmorel 2015). The model finds economically efficient dispatches and optimal capacity investments for the energy system. The emphasis is on the electricity and combined heat and power (CHP) sectors, and the major technologies for electricity, heat generation and storage are included in the model.

The model consists of a set of neighbouring countries that participate in various electricity markets. Each country is then split into one or more regions, depending on the market features, where electricity can be traded with constraints. Denmark, for instance, is modelled using two electricity zones, Denmark East and Denmark West (in the following DK-E and DK-W), according to the NordPool system. The electricity transmission between adjacent zones is limited by a given transmission capacity. Moreover, to model the CHP sector, each electricity region is further divided into several district heating areas.

Time in Balmorel is organized into three step categories: years, seasons (weeks), and individual time units (hours). Each year is composed of 52 weeks and each season is, in turn, composed of 168 time units. The time is however flexible and the user can decide how many seasons and time units to use in the model. The choice depends on the needs for the specific investigation and typically ranges from weeks, when the focus is operational, to years, common for investment analyses. The running time of the model is influenced by the time aggregation used, and varies from minutes to several hours. The main output is, among others, electricity and heat production levels, electricity prices, system costs, electricity transmission, and emissions.

Despite being used in the industry (Balmorel 2015), Balmorel has been applied by the research community to several energy systems worldwide and for a wide range of purposes, from the integration of renewable technologies in the energy mix, to the analysis of market conditions, policies implementation, and future role of district heating in energy systems (Ball et al. 2007, Jensen and Meibom 2008, Karlsson and Meibom 
2008, Münster et al. 2012, Münster and Meibom 2010). Balmorel has also been used to integrate heat savings and residential investment behaviour into the energy systems (Zvingilaite 2013, Zvingilaite and Balyk 2014, Zvingilaite and Klinge Jacobsen 2015).

\subsection{Modelling investments in household appliances}

Consider a set of home appliances $i \in\{1, \ldots, I\}$, and a set of electricity zones $r \in$ $\{1, \ldots, R\}$ where we allow investments in energy-efficient appliances (in our study, DKE and DK-W). To extend Balmorel with EE investments, we need to introduce first the following group of parameters. The assumptions behind data and how data is collected will be topic of the next section.

- $\xi_{i}^{\max }=$ maximum consumption reduction for appliance $i$ with respect to a baseline new, non-EE appliance of the same type and functionality (kWh/year). For example, assume that the average consumption for new, non-EE refrigerators is $300 \mathrm{kWh} /$ year, and the average consumption of the most efficient refrigerators, of same type and functionality, available in the market is $180 \mathrm{kWh} /$ year, then the maximum annual electricity saving from a refrigerator is $\xi_{i}^{\max }=300-180=120$ $\mathrm{kWh} /$ year.

- $c_{i}=$ additional cost of investing in a single appliance $i$ with maximum saving of $\xi_{i}^{\max }$ (EUR) with respect to the cost of a baseline consumption class. For example, assume that the baseline refrigerator efficiency class is $A$ with average cost of EUR 650 , and the most efficient is $A+++$ with average cost of EUR 1000, then $c_{i}=$ EUR 350 .

- $\rho=$ discount rate, used to annuitize the investment cost of new appliances. More comments on the discount rate will follow in the case study.

- $L_{i}=$ average lifetime of appliance $i$ (years). The lifetime is used to annuitize the investment cost and to approximate the annual substitution rate of the appliances, by computing $1 / L_{i}$.

- $N_{i r}=$ estimated number of appliances $i$ in region $r$. It can be approximated by multiplying the share of an appliance with the number of households; for example, if the share of washing machines is 0.80 (items/household) and the number of households in DK-W is $1.4 \mathrm{mln}$., then $N_{i r}$ is $0.80 \times 1.4=1.12 \mathrm{mln}$. Our construction of $N_{i r}$ applies if the total stock of appliances is fixed over time, 
as it is for the Danish market where household growth is very low. For developing economies, such as China or India, $N_{i r}$ should be time-dependent.

- $n_{i r}=N_{i r} / L_{i}=$ estimated number of appliances $i$ in region $r$ which are replaced on average every year (e.g. because they are too old and not well-functioning anymore). For instance, if the average lifetime of a dishwasher is $L_{i}=10$ years and the existing stock in DK-E is $N_{i r}=1 \mathrm{mln}$., then approximately $n_{i r}=0.1$ mln. dishwashers are expected to be purchased in DK-E during a year.

- $d_{i r t}=$ gross electricity consumption $(\mathrm{MWh})$ in region $r$ due to the appliance category $i$ at hour $t$ of the year. We also define the total annual consumption of appliance $i$ in region $r$ as $D_{i r}=\sum_{t} d_{i r t}$, and we will refer to the collection $\left\{d_{i r t}\right\}_{t}$ as the yearly consumption profile of appliance $i$ in region $r$.

We summarize the set of parameters necessary to implement the model in Table 1.

Table 1: Data required to implement the model extension

\begin{tabular}{lll}
\hline Name & Description & For each \\
\hline$\xi_{i}^{\max }$ & Max. consumption reduction & Appliance \\
$c_{i}$ & Extra cost of more efficient appliance & Appliance \\
$L_{i}$ & Lifetime of appliance & Appliance \\
$N_{i r}$ & Stock of existing home appliances & Appliance and region \\
$\rho$ & Discount rate & - \\
$d_{i r t}$ & Hourly consumption profile & Appliance and region \\
\hline
\end{tabular}

It is now possible to compute the annuitized extra investment cost of a new $\mathrm{EE}$ appliance, $c_{i}^{a}[\mathrm{EUR}]$, as

$$
c_{i}^{a}=\frac{\rho c_{i}}{1-1 /(1+\rho)^{L_{i}}} .
$$

Then, we define the decision variables $x_{i r} \in[0,1]$ as the percentage of new appliances of type $i$ that are replaced with the most energy-efficient version in region $r$. In particular, $x_{i r}=0$ means that there is no investment in more efficient appliances of category $i$, while $x_{i r}=1$ means that the full amount $n_{i r}$ of appliances $i$ in the region is upgraded. In this case, the system will benefit of an annual electricity saving of $\xi_{i}^{\max } n_{i r}$ for the lifetime of the appliance.

The introduction of investments in EE has two main effects in the energy system model. First, the investment cost represents a new contribution in the objective func- 
tion, given by

$$
\min : \text { SysCost }+\sum_{i=1}^{I} \sum_{r=1}^{R} c_{i}^{a} n_{i r} x_{i r}
$$

where SysCost is the original objective function in Balmorel representing the total cost of the energy system, and includes the cost of fuel consumption, operation and maintenance cost for the different technologies, investment cost in new generation and storage capacity, emission and fuel taxes, etc. Second, the demand profile is reduced according to the saving associated with $x_{i r}$. The saving is spread over the whole year and applies with the same percentage across the consumption profile of the appliance. We can consequently work hour by hour and, denoting with $d_{r t}$ the electricity demand in region $r$ and time $t$, we define a new power balance equation

$$
\text { (electricity supply in } r \text { at } t)=d_{r t}-\sum_{i=1}^{I} \frac{d_{i r t} \xi_{i}^{\max } n_{i r} x_{i r}}{D_{i r}}
$$

For instance, if there is no investment in EE, meaning $x_{i r}=0$ for all appliances $i$, then the summation term (i.e. the saving) is zero and the equation reduces to the original one. If the investment is maximum for appliance $i$, i.e. $x_{i r}=1$, then the demand is reduced by a factor $d_{i r t} \xi_{i}^{\max } n_{i r} / D_{i r}$. This amount corresponds to the annual saving $\xi_{i}^{\max } n_{i r}$ from appliance $i$, scaled with the fraction of total demand $D_{i r}$ occurring in hour $t, d_{i r t} / D_{i r}$. In line with the other investments in Balmorel, in (2) it is implicitly assumed that new appliances are purchased and installed in the first hour of the year.

In addition, several studies suggest that the gains achieved from new energy saving measures are usually slightly lower than what initially expected, due to the so-called rebound effect (Khazzoom 1980, Carnall et al. 2015, Bulu and Topalli 2011, Shrestha and Marpaung 2006, Galvin 2010, Farinelli et al. 2005, Galarraga et al. 2013). This happens because the consumer typically responds to new EE measures in a way that tends to offset the effects of the changes. In more practical words, if we have a more efficient appliance or service, we tend to use it more because its use is cheaper, and we may also purchase additional appliances of the same type. We include the rebound effect in our model and characterize it as a linear response. Introducing $\beta_{i r} \in[0,1]$ and indicating with $D_{r}$ the total yearly electricity demand in region $r$, we extend (2) with

$$
\text { (electricity supply in } r \text { at } t)=d_{r t}-\sum_{i=1}^{I} \frac{d_{i r t} \xi_{i}^{\max } n_{i r} x_{i r}}{D_{i r}}
$$




$$
+d_{r t} \frac{\sum_{i=1}^{I} D_{i r}}{D_{r}} \frac{\sum_{i=1}^{I} \xi_{i}^{\max } \beta_{i r} x_{i r}}{\sum_{i=1}^{I} \xi_{i}^{\max }}
$$

Even though the magnitude of the effect might change depending on appliance and region, in the following we set all variables to be the same $\left(\beta_{i r}=\beta\right)$.

To summarize, investing in efficient household appliances reduces the electricity consumption as in (3). Less demand implies that less production technologies to operate or install are needed to supply electricity, which in turn implies lower costs for the system. The optimization process will then implicitly compare this economic saving with the investment cost added to (1) and, if convenient, will endogenously trigger the investment.

\subsection{From the energy system to the end-user}

The model presented optimizes investments from a system perspective. It is a socioeconomic analysis and does not include taxes on the consumer side. This means that the solution resulting from the optimization process should be interpreted as the least expensive solution for the whole energy system, and investments in energy-efficient appliances implicitly compete with the supply of electricity at the system price, i.e. wholesale market price. However, the analysis currently disregards a representation of the end-user choices, which are relevant since in practice investments in home appliances are made by end-users. The consumer pays a higher price for electricity due to additional taxes on e.g. transmission, distribution, and policy costs for promotion of renewables. In Denmark, the tax addition to the electricity price is a fixed additive amount that makes the consumer's price up to ten times higher than the system price (Energitilsynet 2016). As a consequence, investments which are not worth for society might be actually profitable for the single user, who individually evaluates an EE investment.

To include the consumer utility in the analysis, we propose the following sequential approach. First, the consumer observes the annual electricity price profile generated from the system model and estimates the consumer price by considering an average overpricing factor. Second, the consumer determines whether investing in more energyefficient appliances is profitable by comparing the extra investment cost with the economic saving implied by the consumption reduction. Third, the energy system model is solved for the second time embedding the investment decisions of the consumer. New electricity prices are generated, and the actual saving on the consumer side is deter- 
mined together with possible changes in the energy system. Figure 1 summarizes the sequential process.

Figure 1: Sequential process to analyse investment decisions for end-users

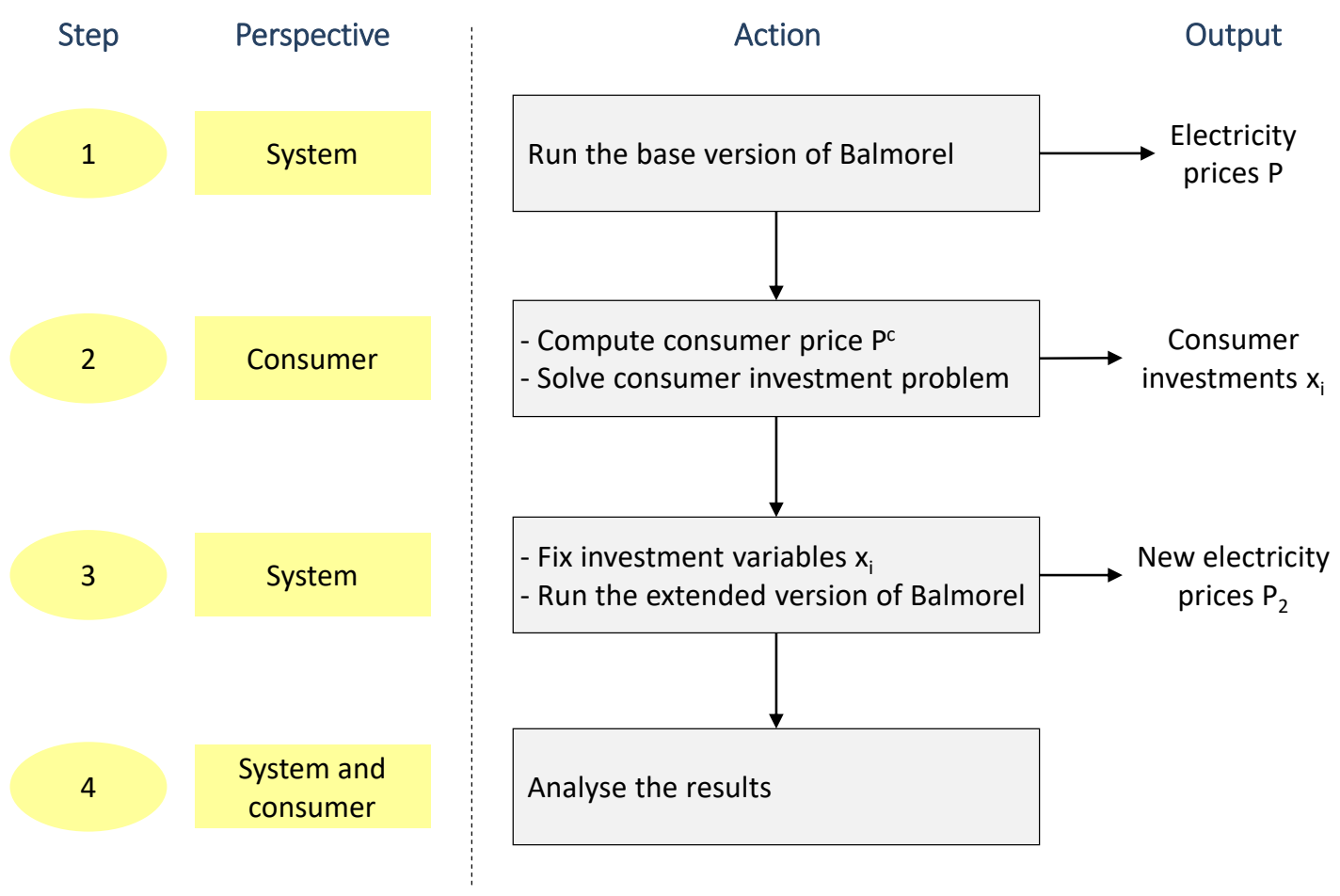

Let us focus on the consumer model. When should a consumer purchase a new energy-efficient appliance, e.g. a refrigerator? If the refrigerator is well-functioning, one would generally need some strong incentive to replace it with a more efficient product. However, as discussed earlier, by introducing a substitution rate we limit the analysis to the sub-group already needing to replace the given appliance due to capital depreciation. Thus, the question we try to answer is more specific: I need to purchase a new refrigerator, should I invest in a very energy-efficient product, paying an extra cost but having an annual energy saving, or should I buy an average refrigerator similar to what I had before? A rational consumer would compare the extra investment cost of the more efficient product with the expected economic saving resulting from the consumption reduction throughout the appliance lifetime, and would undertake the EE investment in case of positive net present value (NPV) of cash flows. In particular, we denote with $p_{r t}$ the system price of electricity, which in Balmorel corresponds to the dual value of the power balance equation, and with $\gamma$ the average price overcharge on 
the consumer side. The consumer price is then estimated by $p_{r t}^{c}=p_{r t}+\gamma$, and the NPV of an EE investment is computed for every appliance $i$ and region $r$ with

$$
\mathrm{NPV}_{i r}=-c_{i}+\sum_{y=1}^{L_{i}} \frac{\alpha_{y}}{(1+\rho)^{y-1}}\left(\sum_{t=1}^{T} p_{r t}^{c} d_{i r t} \xi_{i}^{\max } / D_{i r}\right) .
$$

Equation (4) represents the trade-off between extra investment cost and cumulative annual saving. The expression inside brackets is the economic saving for the current year, calculated by multiplying the consumer price at a given hour $t$ with the consumption reduction achieved in $t$, then summing over the whole year $(T=8760$ is the number of hours in a year). This expression is then summed over a number of years corresponding to the lifetime of the appliance $L_{i}$, discounted, and multiplied by a factor $\alpha_{y}$ indicating the expected change (increase or decrease) of electricity prices for year $y$.

In practice, however, a consumer does not act in a fully economically rational way, and there are behavioural aspects that may influence the investment decision. The consumer behaviour is difficult to capture and model since it is by definition subjective. Previous research tried to quantify the correlation between the propensity to invest in EE (intended as both housing renovation and the purchase of energy-efficient appliances) and factors like income, age and education (Hausman 1979, Mills and Schleich 2010, Ward et al. 2011, Murray and Mills 2011, Allcott 2011b, Davis and E. Metcalf 2014, Houde 2014, Newell and Siikamäki 2013, Schaffrin and Reibling 2015, Bartiaux and Gram-Hanssen 2005). Most of the studies agree on a positive correlation between household's income and investments level. In contrast, conclusions regarding other factors (age, education etc.) often show ambiguity and there is generally no statistical significance in the correlation with investment.

In line with these studies, we include in the model a behavioural uncertainty related to the household's income level. A low-income household might not be willing to pay a high up-front cost for relatively small annual electricity savings. Consequently, even though the EE investment turns out to be profitable according to (4), it may not be undertaken because the payback period is too long. The choice also depends on the other expenses of the households in the same period, i.e. your overall liquidity constraints. On the other hand, the up-front investment cost for a high-income household is typically not a constraint, and, if the EE investment is profitable, then it will be undertaken. It can be seen as a sort of budget constraint and a linear probability model is used to describe it. Moreover, as suggested by some authors (Allcott 2011b, Ward et al. 2011, COOPER 2011), the opposite phenomenon is also possible: a high-income 
consumer may invest in an efficient appliance 'just' because it is the green option, also when the choice is not profitable from a strictly economic perspective. Thus, similarly as before, we assign a probability of purchasing the energy-efficient appliance when the investment is not profitable.

The curves in Figure 2 represent the probability of purchasing an energy-efficient product when economically profitable and when not. They are constructed partly based on the results from Allcott (2011b), Ward et al. (2011), COOPER (2011) and partly by using data about income and annual expenditure in appliances by households from Statistics Denmark (2016). The curves are employed as model assumptions as no empirical evidence for the functional slope is available in the literature. We also assume that the curves are not static but dependent on the specific appliance: if the NPV is positive but the payoff takes many years, then the blue curve shifts down, and vice versa. In the analysis, we are not incorporating possible variations of the number of appliances and replacement rate by income class, and we equally split the stock among the classes.

Figure 2: Probability of purchasing an energy-efficient appliance when economically profitable (blue line) and when not profitable (red line). On the $x$-axis are the deciles of the income distribution of Danish households.

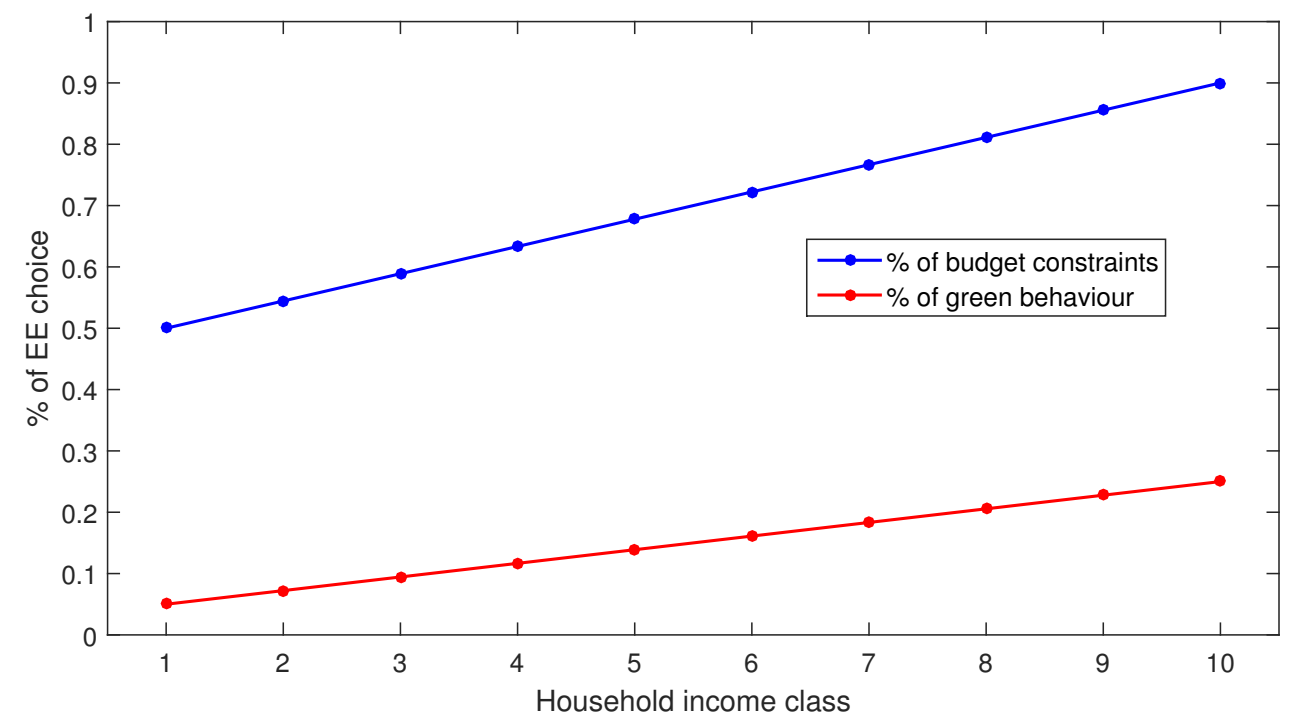

In reality, the consumer choice is also subject to uncertainty regarding the information available (e.g. electricity prices and products on the market) and errors in computing the economic convenience. This uncertainty is already included in the consumer model, indeed, for instance, the adoption rate of profitable products by the 
highest income class is lower than $100 \%$.

Coming back to the sequential approach, notice that also other authors have incorporated consumer classes (income deciles) with different behavioural profiles into a model which ultimately solves as a system optimization, for example Bunch et al. (2015). We conclude the section with a few remarks.

1. After new electricity prices are generated, the end-user's model could be executed once again leading to a potentially different investment decision. This new decision could be plugged into the system model, and the sequential approach iterated until convergence (i.e. when there are no changes in electricity prices between two iterations). However, in all our experiments the model converged after the first iteration, thus we neglect the convergence topic in the following discussion.

2. In (4) savings are modelled using flexible electricity pricing. Even though most of the Danish households currently pay electricity based on a flat tariff (Energitilsynet 2016), in the last few years smart meters have been spreading, reaching almost 50\% of the of the Danish households in 2015 and aiming at $100 \%$ for 2020 (Danish Ministry of Energy Utilities and Climate 2013, 2014). With smart meters and exposition to real-time rates, the adoption of flexible pricing is expected to quickly increase (Allcott 2011a, Katz et al. 2016, Katz 2014, Krishnamurti et al. 2012, Broman Toft et al. 2014, Faruqui et al. 2010).

\section{Case study}

The proposed model extension has been tested on the Danish energy system. However, the test is non-exclusive, and the same analysis could be performed on a different system, provided that all the input data needed to run the model is available.

\subsection{Scenario description}

We characterize the scenarios based on three main elements on the input side: simulation year, fuel price forecast, and fuel availability. Two different simulation years are considered:

- 2015: serves as an ex-post analysis to understand how the known energy system would have changed if consumer (or society) had invested in EE in an optimal way. For this case, the system is fully determined exogenously and we do not 
allow investments in new power plants. Thus, the model is in an operational simulation mode.

- 2025: to assess the saving analysis on a future energy system. For this case, the energy system is also allowed to evolve by endogenously investing in new power plants and decommissioning the old and unproductive ones.

To cope with the uncertainty in fuel and emission prices in 2025, following Zvingilaite (2013) we identify a range of price values presented in Table 2: from a low price scenario to a high price scenario. The low price scenario has been constructed with the guidelines of the Danish Energy Agency for future socio-economic analyses (Danish Energy Agency 2016b). The high price scenario is based on the oil price development in Oilprice.com (2016) and IEA (2016), with the assumption that the high prices for other fuels follow the price of oil with certain elasticity, as indicated e.g. in Karlsson and Meibom (2008). The cost of municipal waste is assumed to be negative and constant, since in Denmark, the waste incineration plants are paid to treat the waste (Münster 2009). Regarding $\mathrm{CO}_{2}$, the low price scenario is based on the carbon trading price, which in fall 2009 was around $15 \mathrm{EUR} / \mathrm{t}$ (Reuters 2016), whereas the high price scenario is based on the IPCC considerations (Ipcc 2007). In the table, we also report the average price scenario.

Table 2: Prices of fuels and emissions in 2025 according to different scenarios. Prices for renewable sources, e.g. wind, sun and hydro, are assumed to be zero.

\begin{tabular}{lrrr}
\hline & $\begin{array}{r}\text { Low price } \\
(\mathrm{EUR} / \mathrm{GJ})\end{array}$ & $\begin{array}{r}\text { Average price } \\
(\mathrm{EUR} / \mathrm{GJ})\end{array}$ & $\begin{array}{r}\text { High price } \\
(\mathrm{EUR} / \mathrm{GJ})\end{array}$ \\
\hline Fuel oil & 13.33 & 17.24 & 21.14 \\
Natural gas & 12.01 & 15.02 & 18.02 \\
Municipal waste & -3.60 & -3.60 & -3.60 \\
Coal & 5.05 & 6.97 & 8.89 \\
Wood pellets & 12.25 & 13.03 & 13.82 \\
Straw & 7.69 & 8.47 & 9.25 \\
$\mathrm{CO}_{2}[\mathrm{EUR} / \mathrm{t}]$ & 18.02 & 39.04 & 60.07 \\
\hline
\end{tabular}

In addition, we model availability constraints on the main input fuel sources for 2025. The limitations are decided according to the 4 degree scenario proposed by the IEA in the Nordic Energy Technology Perspective (IEA 2016). Table 3 reports the most relevant values. 
Table 3: Fuel availability for 2025 (fuel input for power, heat and CHP plants), NETP (IEA 2016)

\begin{tabular}{lrrrr}
\hline & DK & SE & NO & FI \\
\hline Coal (PJ) & 99.2 & 9.4 & 0.0 & 87.8 \\
Oil (PJ) & 1.9 & 4.4 & 0.1 & 1.7 \\
Gas (PJ) & 21.4 & 3.6 & 0.0 & 34.8 \\
\hline
\end{tabular}

The scenarios are tested using four representative weeks of the year (weekw 09, 22, 32 , and 51), where each week is composed by the full hourly resolution (168 h), giving a total of 672 time steps for the simulation. In this way, we are able to obtain sufficiently accurate results, keeping the size of the model and its running time limited. The hourly resolution is needed here to entirely capture the differences of consumption profiles of the various home appliances.

\subsection{Relevant parameters}

A set of input data for each of the two Danish electricity zones must be collected. In Table 4 we report some of the most relevant parameters along with the reference.

Table 4: Relevant model parameters: values and references

\begin{tabular}{llrl}
\hline Data & Zone & Value & Source \\
\hline Electricity demand (TWh) & DK-E & 13.70 & NordPoolSpot (2016) \\
Electricity demand (TWh) & DK-W & 20.44 & NordPoolSpot (2016) \\
Number of households (mln.) & DK-E & 1.15 & Statistics Denmark (2016) \\
Number of households (mln.) & DK-W & 1.41 & Statistics Denmark (2016) \\
Electricity tax addition (EUR/MWh) & DK & 265 & Energitilsynet (2016) \\
Discount rate (\%) & DK & 3 & Danmark NationalBank (2016) \\
Rebound effect (\%) & DK & 3 & Nässén and Holmberg (2009) \\
\hline
\end{tabular}

Nowadays, the risk-free investment rate in Denmark is very close to zero (Danmark NationalBank 2016). However, in our analysis we also account for the expected uncertainty from EE investments (given e.g. fuel price volatility and regulatory uncertainty). Therefore, $\rho$ is increased and set equal to 3\%, like the value used in Zvingilaite (2013) for heat saving investments in Denmark. The magnitude of the rebound effect related to EE, a debated topic in the literature, can vary from moderate to negligible levels depending on the analysis. In our model, we use a rebound effect level of $3 \%$ related 
to household electric appliances (Nässén and Holmberg 2009). The tax addition to the electricity system price in Denmark is estimated to be $265 \mathrm{EUR} / \mathrm{MWh}$ according to Energitilsynet (2016), and is expected to remain stable in the near future.

\subsection{Appliances data}

We selected the subset of 11 home appliance categories listed in Table 5. This set is chosen for several reasons. First of all these devices, together, constitute approximately $80 \%$ of the electricity demand of the private household sector in Denmark; hence, they are the most interesting to study from an energy consumption perspective. The electricity demand of residential air-conditioning systems, for instance, is negligible in the Danish context, and such appliance is therefore excluded from the study. Second, given the high energy consumption of the chosen appliances, the price of purchasing a new product reflects in a good extent its efficiency: when buying e.g. a new refrigerator of a given volume, the energy use of the product is typically the main factor driving the choice. On the other hand, for more high-tech appliances such as desktops, laptops, and printers, this is generally not true, and price difference between two products or brands is given by the functionalities rather than the consumption. Third, most of the selected appliances fall under the EU energy labelling programme, therefore it is easier to collect the relevant data and assess the relationship between price and efficiency.

Table 5: List of household appliances considered in the analysis. The second and third columns refer to the annual consumption reduction and extra cost with respect to an average consumption class.

\begin{tabular}{lccc}
\hline Appliance category & Saving $[\mathrm{kWh} / \mathrm{y}]$ & $\Delta$ cost [EUR] & lifetime [years] \\
\hline Stand-alone refrigerator & 50 & 413 & 15 \\
Stand-alone freezer & 88 & 138 & 20 \\
Refrigerator-freezer & 152 & 605 & 17 \\
Washing machine & 109 & 242 & 12 \\
Dish washer & 65 & 572 & 10 \\
Dryer & 118 & 605 & 13 \\
Lighting living room & 29 & 9 & 6 \\
Lighting secondary rooms & 25 & 9 & 7 \\
Cooker & 52 & 435 & 12 \\
TV LCD & 24 & 243 & 7 \\
Vacuum cleaner & 11 & 130 & 7 \\
\hline
\end{tabular}


The saving and cost data in Table 5 are averages over different products and brands, but with same volume or size, taken from some of the major producers and retailers active in Denmark (Bosch, Siemens, Electrolux, Miele, Aeg etc.). In the table, cooker refers to both electric hobs and electric baking oven. The lighting system is split in two components to account for the different use: one main room (living room) with an higher usage and the other secondary rooms. The extra cost is generally rather high since we model investments in appliances with the highest available efficiency class (e.g. $\mathrm{A}++$ or $\mathrm{A}+++)$. Limiting the investment analysis to Denmark, we assume there are no differences in the performance or cost characteristics of existing or new appliances between the two regions DK-E and DK-W.

The presented model uses linear cost-efficiency relations for appliances, i.e. the purchasing cost of an appliance grows linearly with the consumption reduction. In practice, there may be differences between the appliances and more complex cost-efficiency relations. However, the data collected supports the assumption that a linear fitting describes the relation sufficiently well for our purposes. Figure 3 illustrates the costefficiency relation for two sample appliances.

Figure 3: Cost-efficiency relations for refrigerators (left) and dishwashers (right), classes $\mathrm{A}+$ to $\mathrm{A}+++$. The dots represent average cost and consumption of a number of products of the same efficiency class; the blue line is the linear interpolation between them.
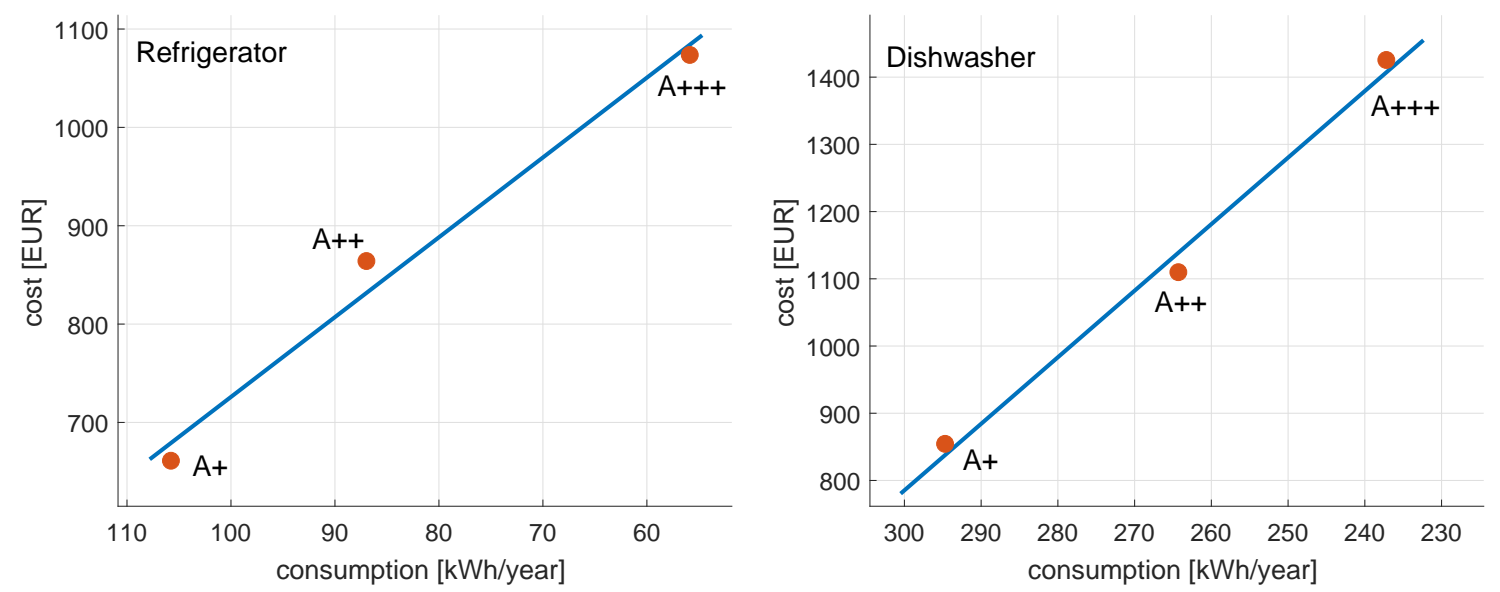

Regarding demand profiles, we rely on the results from Klinge Jacobsen and Juul (2015) who investigated the electricity consumption of a typical Danish household and determined consumption profiles for each appliance category. The profiles of the 11 appliances included in the analysis are illustrated in Figure 4, summing DK-E and DK-W. 
As expected, the profile changes considerably between the different categories. For example, the cold appliances (refrigerator, freezer) manifest a fairly flat profile while other appliances like lighting more contribute to the peaks, especially during the evening hours. Differences can be also found between working days and weekend: in the weekend the kitchen equipment is used more, in particular during lunch hours, and the use of the vacuum cleaner is higher too.

Figure 4: Electricity consumption profile during a sample week (week 09) of the 11 home appliances included in the analysis.

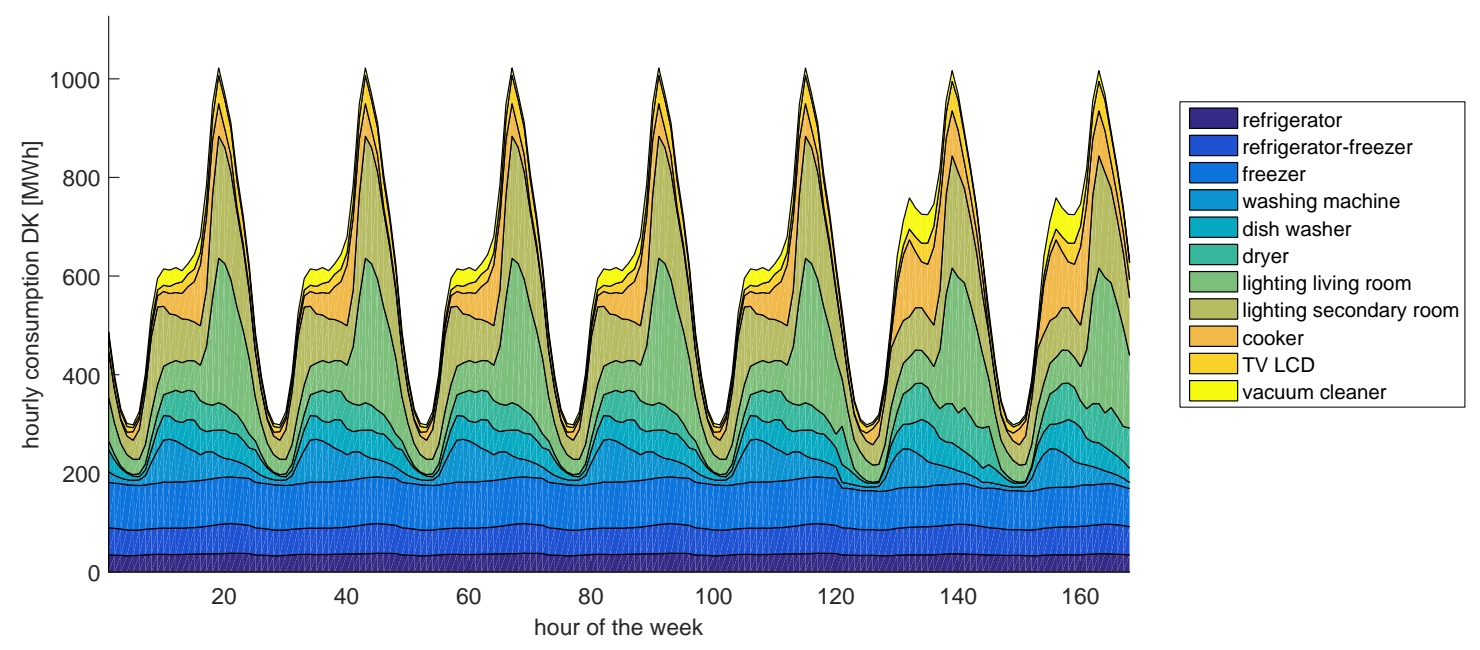

In Figure 5, we show how the aggregated profile of the 11 appliances contributes to the total electricity demand of households and of all sectors in Denmark.

\section{Results and discussion}

A sensitivity analysis of the model using fuel and $\mathrm{CO}_{2}$ costs for 2025 reported in Table 2 was made, resulting in similar electricity prices $p_{r t}$ (although a different capacity mix is installed). This limited local sensitivity to scenario prices occurs because, given the replacement rate, only a small component of the energy demand is affected by the EE investments. As a consequence, we noticed no or very little change in the consumer choices (but different $\mathrm{CO}_{2}$ implications) and, throughout the section, we will present the results for the average cost scenario for 2025. 
Figure 5: Aggregated profile of the 11 appliances compared to the total electricity demand in a sample week (week 09)

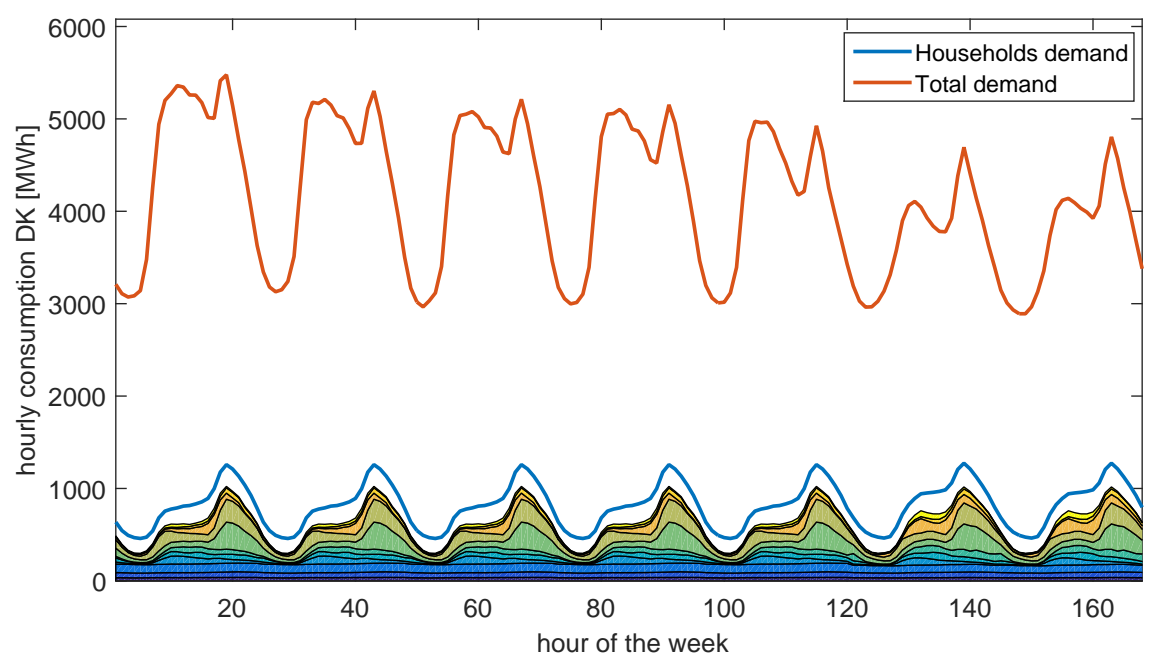

\subsection{Preliminary check}

The driver for the investment choice lies in the economic profitability of adopting a particular appliance, based on the cumulative savings achieved during its entire lifetime. To get a first idea of the potential of investing in the different appliances, in Figure 6, we compute the amount of energy per unit that could be saved if an EE investment of 1 EUR is made in one of the examined appliances.

As can be seen, the gap between lighting and other appliances is large: investing 1 EUR in lights results in an annual saving of around $3 \mathrm{kWh}$, while for other appliances it ranges from 0.1 to $0.6 \mathrm{kWh}$, i.e. an order of magnitude lower. Excluding lighting, from the picture, it emerges that freezer and washing machine provide the best saving per unit investment, compared to the rest of the stock. Although Figure 6 gives a picture of the potential benefit of investing in the different devices, the final investment choices also depend on the hourly electricity price and the consumption profile of each specific appliance.

\subsection{EE investments}

The investments in EE appliances resulting from the simulations are shown in Figure 7. The left graph illustrates the optimal levels when the system model with endogenous investments is used, whereas the right graph represents the consumer choices after the 
Figure 6: Annual electricity saving per 1-EUR investment.

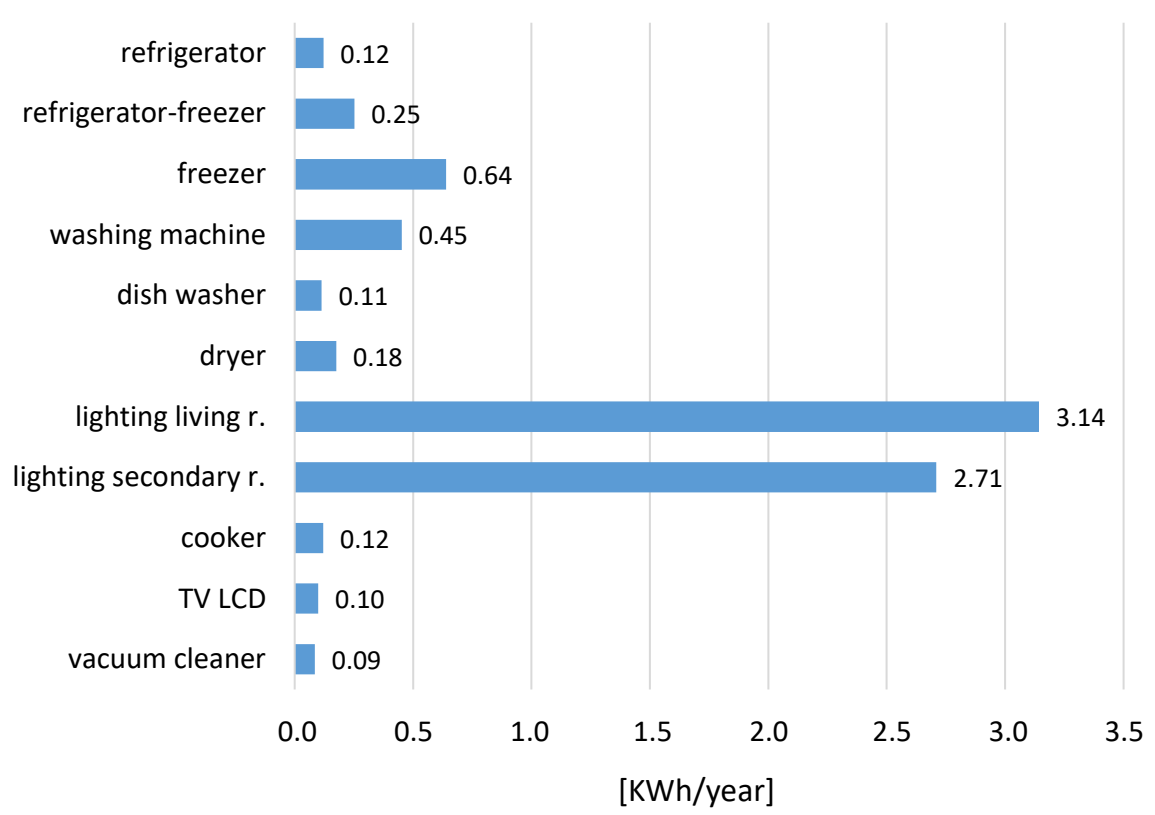

sequential model is run. In the following, the values for DK-E and DK-W are presented as merged, even though they are separate zones from a model logic.

Figure 7: Investments in efficient appliances with the system model (left) and consumer model (right). The amount on the $x$-axis corresponds only to the extra cost with respect to the baseline efficiency class, and not to the overall investment cost in new appliances.
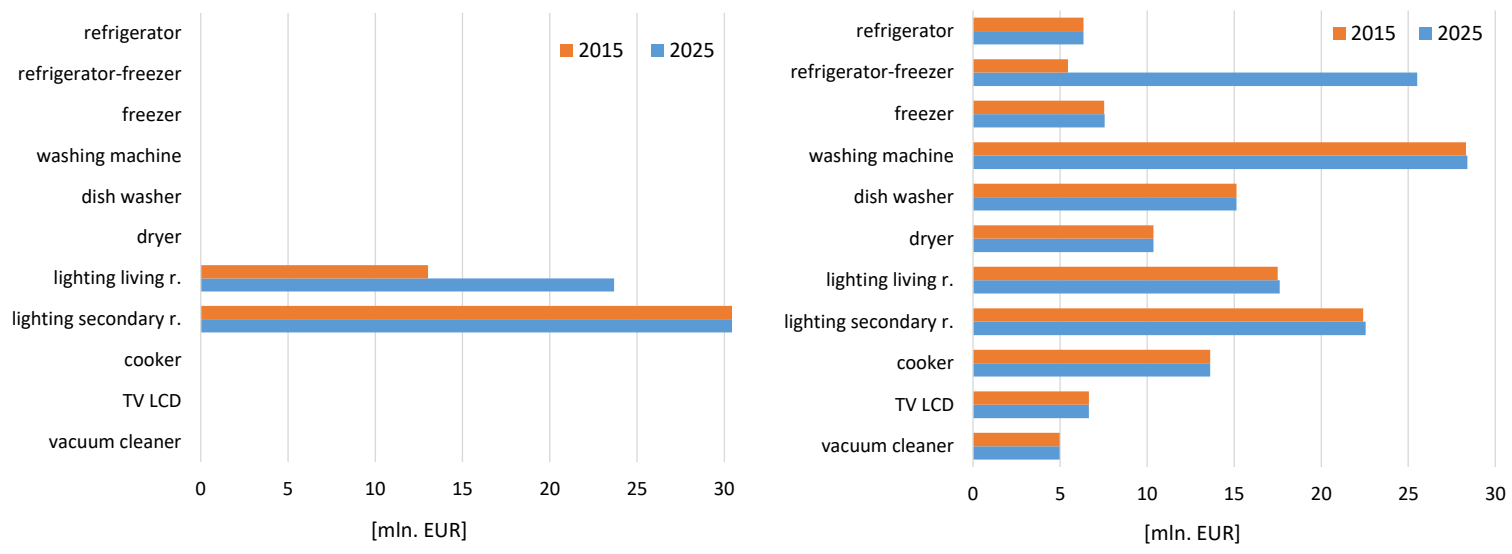

When the system is considered, the economic/energy saving criterion shows that the only EE investments worth doing are efficient lighting replacements. For 2025, 
the investment level in lighting for the living room is higher than 2015 due to the corresponding higher system prices of electricity for that year. This price difference develops because the system prices for the future energy system include long-term investments in renewable technologies and other system adjustments. Finally, given the lower saving per unit cost, no investment in other EE appliances is triggered during the optimization process.

In contrast, the end-user economic convenience is based on the consumer electricity price and more diversified investments occur. Due to the consumer's behavioural dimension and the incompleteness of information, however, not all investments with positive NPV are undertaken, and vice versa, some investments in appliances with negative NPV occur. For instance, the investment level in lighting for secondary rooms $(\mathrm{NPV}>0)$ are lower than $100 \%$ (as they are in the system model), and some investments in EE refrigerators $(\mathrm{NPV}<0)$ take place. The consumer investments in EE exceed the system investments by $95 \mathrm{mln}$. EUR in 2015 and $105 \mathrm{mln}$. EUR in 2025 .

Overall, the two years investigated show small differences in consumer choices, and investments in 2025 are only slightly higher than those in 2015. Indeed, even if the system prices of electricity are higher in 2025, the additive nature of the tax component makes the difference perceived by consumers less pronounced. The combined refrigerator-freezer represents an exception; in fact, the NPV becomes positive for some consumer classes between the two years, leading to a substantial increase for 2025 .

To better understand the results, in Figure 8, we compare the lifetime of a new and more efficient household electric device with the discounted payback period (DPP) of its extra investment cost, i.e. the time needed for the EE investment to break even. As can be seen, the DPP of an efficient lighting is approximately 1 year, for freezer and washing machine, it is about 5 and 8 years, respectively, and for all other appliances, it is longer than 15 years. For a rational consumer with no liquidity constraints, an investment is deemed worthy if the DPP is lower than the lifetime of the appliance, meaning that the appliance will be paid-off before the end of its expected lifetime (this is the same to having a positive NPV). The analysis shows that this criterion applies for lights, stand-alone freezers, washing machines, and combined refrigerator-freezers which are at the borderline. Specifically, one can notice that, although similar savings can be achieved with efficient washing machines and dryers (Table 5), the investment profitability differs substantially. Indeed, the most energy-efficient dryers are still very expensive, and the extra investment cost is higher than in washing machines. Moreover, among the cold appliances, we notice that the profitability of EE freezers is higher than that of EE refrigerators. 
Figure 8: Lifetime versus discounted payback period (discount rate 3\%) in the consumer perspective.

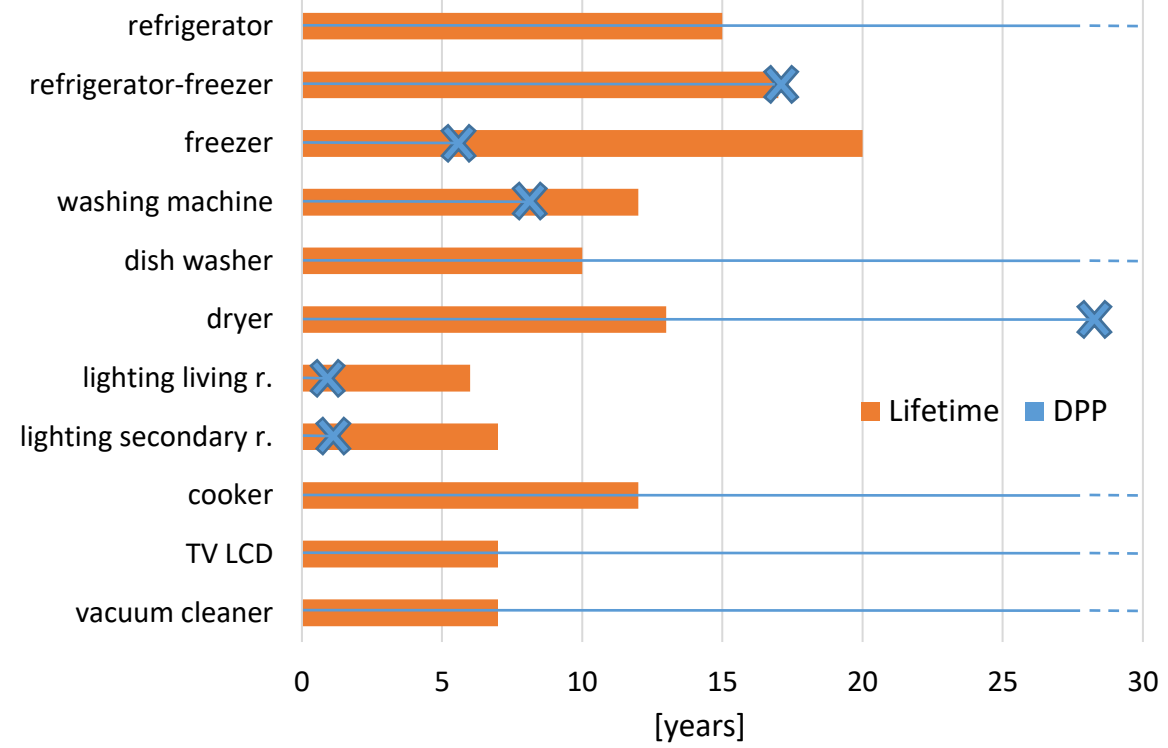

Table 6: Summary table for the scenarios analysis, 2015 and 2025

\begin{tabular}{lcccccccc}
\hline & \multicolumn{2}{c}{$\begin{array}{c}\text { Investments } \\
\text { [K units] }\end{array}$} & \multicolumn{2}{c}{$\begin{array}{c}\text { Investments } \\
\text { [mln. EUR }]\end{array}$} & \multicolumn{2}{c}{$\begin{array}{c}\text { Economic savings } \\
\text { Amln. EUR] }\end{array}$} & \multicolumn{2}{c}{$\begin{array}{c}\text { Electricity } \\
\text { savings }[\mathrm{GWh} / \mathrm{y}]\end{array}$} \\
\cline { 2 - 9 } Appliance & 2015 & 2025 & 2015 & 2025 & 2015 & 2025 & 2015 & 2025 \\
\hline Refrigerator & 15.4 & 15.4 & 6.3 & 6.3 & 0.22 & 0.25 & 0.77 & 0.77 \\
Refr.-freez. & 9.0 & 42.2 & 5.5 & 25.5 & 0.40 & 2.13 & 1.37 & 6.42 \\
Freezer & 54.6 & 54.7 & 7.5 & 7.6 & 1.39 & 1.60 & 4.80 & 4.82 \\
Wash.mach. & 117.0 & 117.3 & 28.3 & 28.4 & 3.71 & 4.33 & 12.76 & 12.79 \\
Dish washer & 26.5 & 26.5 & 15.1 & 15.1 & 0.50 & 0.58 & 1.72 & 1.72 \\
Dryer & 15.4 & 15.4 & 10.4 & 10.4 & 0.53 & 0.61 & 1.81 & 1.81 \\
Light L.R. & 1892 & 1904 & 17.5 & 17.6 & 16.00 & 19.03 & 54.87 & 55.23 \\
Light S.R. & 2423 & 2438 & 22.4 & 22.6 & 17.67 & 20.97 & 60.57 & 60.95 \\
Cooker & 31.4 & 31.4 & 13.6 & 13.6 & 0.47 & 0.56 & 1.63 & 1.63 \\
TV LCD & 27.4 & 27.4 & 6.7 & 6.7 & 0.19 & 0.22 & 0.66 & 0.66 \\
Vacuum cl. & 38.4 & 38.4 & 5.0 & 2.2 & 0.12 & 0.14 & 0.42 & 0.42 \\
\hline Total & 4650 & 4711 & 138.3 & 156.0 & 41.2 & 50.4 & 141.4 & 147.2 \\
\hline
\end{tabular}

In Table 6, we report the details of the investments, quantifying the adoption and effectiveness of energy-efficient appliances. Consider for instance 2015: with an up-front 
extra cost of $138 \mathrm{mln}$. EUR, the resulting energy and economic savings is $141 \mathrm{GWh}$ and $41 \mathrm{mln}$. EUR per year respectively. Including the lifetime of the appliances and the discounting, this translates into revenues of $222 \mathrm{mln}$. EUR, i.e. a net discounted saving equal to $84 \mathrm{mln}$. EUR for Danish consumers investing in energy-efficient appliances (similar for 2025).

In Table 7, we report the analysis of the benefits on the consumer side, highlighting the annual economic and energy savings resulting from the investments. The saving for 2025 is slightly higher because of the higher electricity prices. Notice that the saving is spread over the entire Danish population, disregarding the fact that only a portion of it is actually replacing a given appliance.

Table 7: Average electricity and economic saving for Danish households

\begin{tabular}{ccccc}
\hline Year & $\begin{array}{c}\text { Extra-investment } \\
\text { costs (EUR) }\end{array}$ & $\begin{array}{c}\text { Annual electricity } \\
\text { saving (kWh/year) }\end{array}$ & $\begin{array}{c}\text { Annual economic } \\
\text { saving (EUR/year) }\end{array}$ & $\begin{array}{c}\text { Net economic } \\
\text { saving (EUR/year) }\end{array}$ \\
\hline 2015 & 54.0 & 55.2 & 16.1 & 32.5 \\
2025 & 62.0 & 57.5 & 19.7 & 44.2 \\
\hline
\end{tabular}

In the methodology section, we discussed the ability to afford investments according to the income class. In Figure 9, we illustrate the investment levels for each appliance disaggregated per class. The graph shows that the higher the income, the higher the share of the investment, reflecting the trends defined in the linear consumer model of Figure 2. 
Figure 9: Investments in energy-efficient appliances according to the income class (2025)

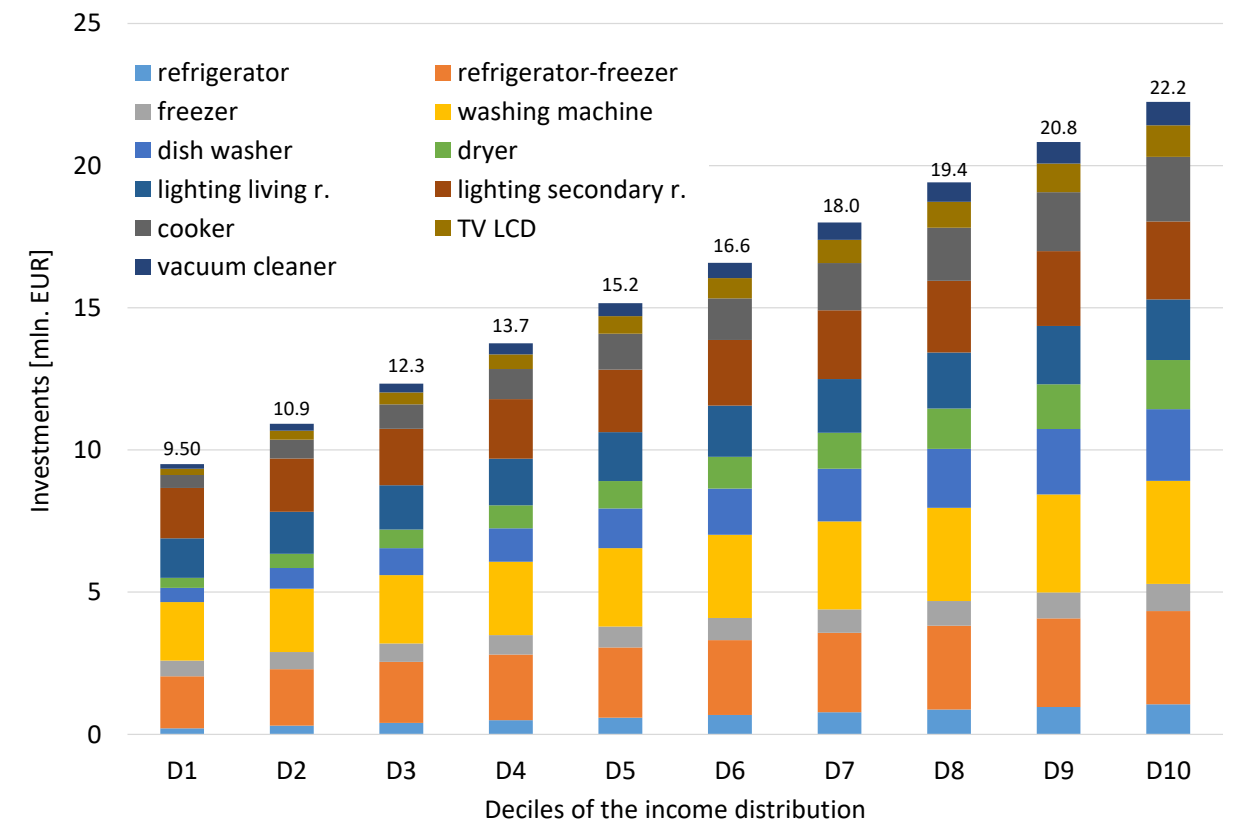

\subsection{System changes and comparison of perspectives}

One of the main purposes of modelling the consumer behaviour is to determine its impact on the energy system. To assess the changes, we focus on two key parameters, $\mathrm{CO}_{2}$ emissions and electricity demand reduction, and summarize the results in Table 8.

Table 8: Total electricity and $\mathrm{CO}_{2}$ savings.

\begin{tabular}{|c|c|c|c|c|c|c|}
\hline & \multicolumn{3}{|c|}{ Electricity savings } & \multicolumn{3}{|c|}{$\mathrm{CO}_{2}$ savings } \\
\hline & $\begin{array}{c}\text { Amount } \\
(\mathrm{GWh})\end{array}$ & $\begin{array}{l}\% \text { house- } \\
\text { holds DK }\end{array}$ & $\% \mathrm{DK}$ & $\begin{array}{c}\text { Amount } \\
\left(\mathrm{Kton} \mathrm{CO}_{2}\right)\end{array}$ & \% system & $\% \mathrm{DK}$ \\
\hline 2015 Sys & 123 & 1.88 & 0.38 & 83.7 & 0.020 & 0.34 \\
\hline 2015 Cons & 141 & 2.15 & 0.43 & 117.2 & 0.030 & 0.48 \\
\hline 2025 Sys & 157 & 2.44 & 0.49 & 32.8 & 0.017 & 0.87 \\
\hline 2025 Cons & 147 & 2.29 & 0.46 & 19.2 & 0.010 & 0.51 \\
\hline
\end{tabular}

For 2015, we notice that introducing a consumer model leads to higher electricity savings compared to the optimal system investments (141 GWh vs. $123 \mathrm{GWh})$. With the implemented savings, Denmark could cut its $\mathrm{CO}_{2}$ emissions of almost $0.48 \%$ according to the consumer model. Although this percentage seems small, the reader should keep 
in mind that a similar saving will occur in the years succeeding the investment. Considering the lifetime of the appliances and the substitution rate of the yearly stock, the cumulative savings will result higher in the long term.

A different configuration emerges for 2025 where the level of electricity savings achieved in both models is higher than that in 2015. Nevertheless, the total amount of $\mathrm{CO}_{2}$ reduction is lower. Indeed, the future energy system in 2025 will be highly based on renewable energy sources, especially wind, and several fossil fuels power plants will be decommissioned by then. Although the emissions reduction is lower, we notice that in percentage we obtained a $\mathrm{CO}_{2}$ cut of almost $1 \%$, implying a larger impact of the savings on the system. Moreover, for 2025, the savings achieved are higher in the system perspective. Indeed, in the system model, more investments in lights take place which, as shown in Figure 6, contribute more effectively to the electricity demand reduction.

Figure 10: $\mathrm{CO}_{2}$ emissions reduction in 2015 (left) and 2025 (right).
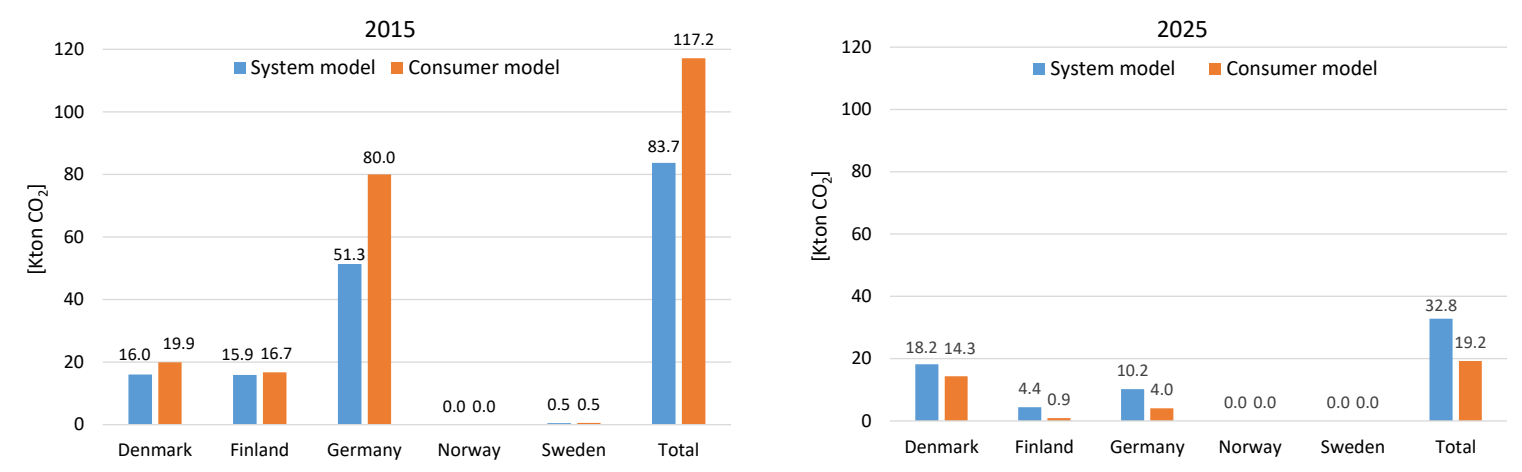

Figure 10 provides a graphical representation of the emissions reduction divided by country. It is interesting to see that, although a demand reduction via EE was implemented in the model only for Denmark, the decrease in $\mathrm{CO}_{2}$ emission takes place in several other countries connected with Denmark. This highlights the influence of the interconnections between countries and proves that changes occurring in the Danish system have an impact on the electricity production not only of Denmark itself but also of the other countries. For 2015, the largest emissions reduction occurs in Germany, where the simulation shows that future use of nuclear, natural gas, coal, and lignite decreases while the power production from wind, wood pellets, and municipal waste increases. Denmark comes after together with Finland; energy mix highly based on hydro and nuclear power, as Norway and Sweden, is not greatly influenced by small changes in the demand of a surrounding country. For 2025, instead, Denmark con- 
tributes more to the total $\mathrm{CO}_{2}$ emissions reduction with 55 and $74 \%$ for the system and consumer perspectives, respectively.

The EE investments also affects the electricity consumption profile, as reported in Figure 11 for a sample week. The two different models, system and consumer, influence the demand in diverse ways. As can be noticed, the investments in the system model are entirely based on lights and mainly contributes to reducing the peaks. This is also in line with results from previous studies (Klinge Jacobsen and Juul 2015). In contrast, being the consumer's investments more diversified, the demand is reduced homogeneously through the year, including hours outside peak loads.

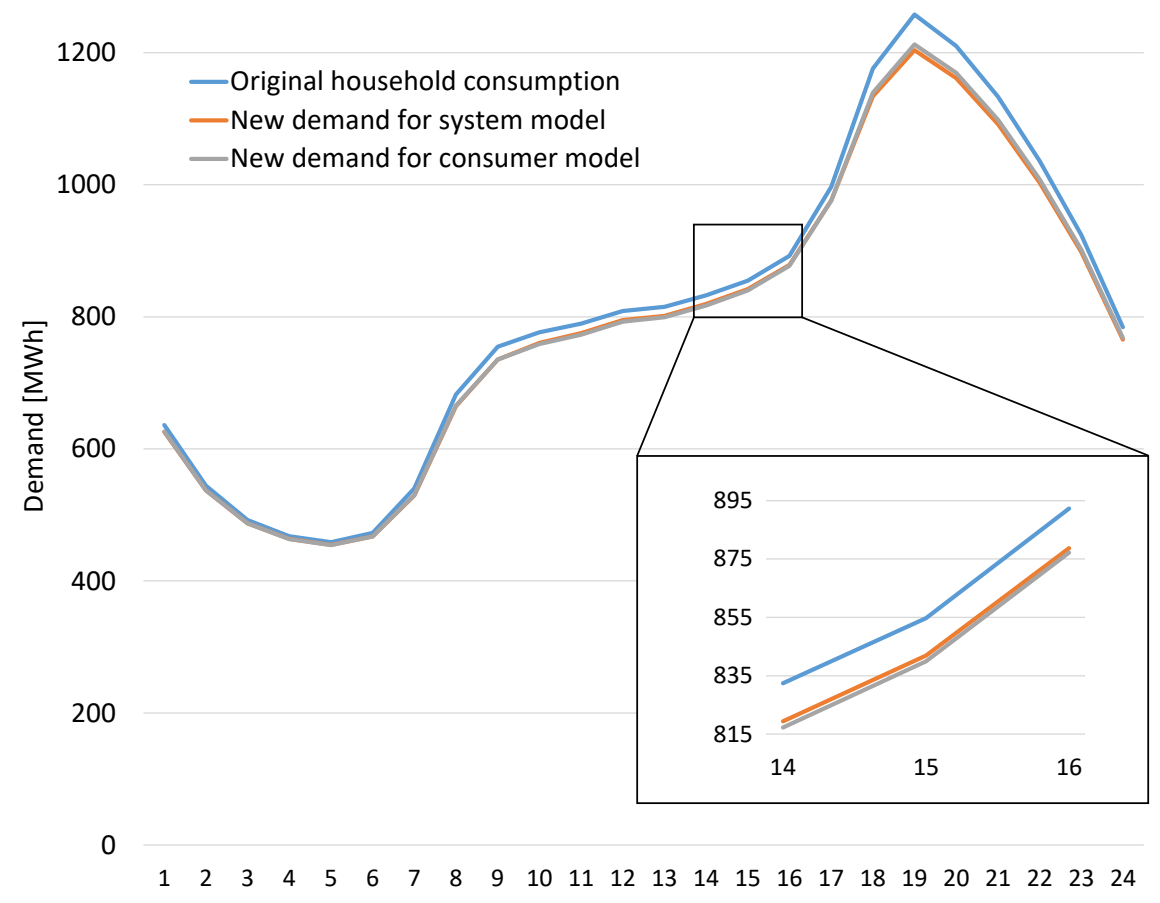

Figure 11: Electricity demand after system and consumer investment models (week 09, day 1).

Even though investments are generally higher and more variegated for the consumer model, the overall demand reduction is similar in the two cases. In fact, the slightly higher investment in efficient lighting for the system model results in total savings comparable to that of all the other appliances chosen by consumers together. 


\section{Conclusions}

The goal of this paper was to investigate the value of investments in more energyefficient home appliances compared to a business-as-usual electricity supply scenario.

Two different perspectives have been examined: energy system and end-user. When the system is given the possibility to invest in efficient appliances, only investments in the lighting sector take place. In contrast, when the consumer has the choice, the investments are more diversified and generally higher. This highlights the different selection criteria for the two models: the system considers purely economical convenience, whereas for consumers a behavioural dimension comes into play. Moreover, two main factors have been considered when modelling the choices of the end-users: economic profitability and 'green investments' propensity according to the income class. This last component, together with the different electricity prices, represents the reason for the diverse investments compared to the system perspective.

The findings presented in the paper are the result of a soft-linking between a wellknown energy system model and a consumer-behaviour model designed for the study. The interactions between the two models is the key for understanding the impact of the consumer choices on the energy system. When compared to a business-as-usual energy scenario, with the investment solution resulting from the model, the end-user ends up on average with a net economic savings in the range of 30-40 EUR per year. Moreover, the system benefits of a total electricity savings of 141 GWh in 2015 and 147 GWh in 2025, and $\mathrm{CO}_{2}$ emission reduction of 117 Kton in 2015 and 19 Kton in 2025. Because of the international interconnections and energy markets, changes in the energy system (e.g. in installed capacity, fuel consumption, emissions) occur not only in the country the consumer belongs to, but also in the surrounding countries. The decision of a single consumer, thus, contributes to the diversification and transformation of the global energy system.

The study also reveals the potential appliances that will be attractive from a system perspective and, despite the simplicity of the consumer choice model, it provides a first indication of the profitability of investments for private consumers. The closing considerations have highlighted the relevance of this analysis for a country that is aiming at important targets in terms of environmental issues. Therefore, this study should be pushed forwards. 


\subsection{Future work}

The presented study could be extended in several key directions. One way is to include a more sophisticated consumer behaviour into the investment decision function. The data from a survey conducted from the Danish Energy Agency ${ }^{1}$ over a representing set of houses serve as the starting point for the new thorough analysis. Using this dataset, an exclusive, latent class logistic model could be employed to categorize the consumers into subsets with respective propensities to purchase (Shen and Saijo 2009, Murray and Mills 2011, Mills and Schleich 2010). This could also help to better assess the functional slope of the purchase propensity by income class proposed in this paper. Using different discount rates could also be a natural way to incorporate several of the behavioural differences that are noted between consumer income classes. Of additional interest, Danish specific data and appliance purchasing behaviour is currently under investigation by UserTEC (2016) and could potentially be included. The end goal intended is then to incorporate the consumer categories into Balmorel to compute a more realistic energy savings scenario.

Additionally, this analysis can be extended to re-examine the efficacy of Denmark's imposed policies (i.e. EU driven energy labelling programme and overall energy efficiency targets). Analyses in 2013 (Danish Energy Agency 2016a) predicted savings of $5640 \mathrm{GWh} /$ year by the year 2020 as a result of ecodesign requirements and the labelling programme. With updated data on actual adoption, these projections can be re-examined. Additionally, these propensity estimates can inform investigation into the potential benefits of energy-efficient appliance support schemes.

Another avenue could be to explore the interaction and/or trade-off between reduced consumption and smart consumption. Indeed, in a decentralized system, EE means not only energy consumption reduction anymore, but also smart energy consumption. Denmark is still committed to equipping every household with a smart electricity meter by 2020. Despite much interest in intelligent demand response, such a sporadic system could diminish the service aspect of energy use. Thus, a comparative analysis into the savings provided by smart use versus efficient investment could be explored via Balmorel.

\footnotetext{
${ }^{1}$ At the time of the article writing (October 2016), this data is not available and is expected to be released in the upcoming months.
} 


\section{Acknowledgments}

The research has been financed by the Innovation Fund Denmark under the research project SAVE-E, grant no. 4106-00009B.

\section{References}

Allcott, Hunt. 2011a. Rethinking real-time electricity pricing. Resource and Energy Economics 33(4) 820-842. doi:10.1016/j.reseneeco.2011.06.003. URL http://dx.doi.org/ $10.1016 / j$.reseneeco.2011.06.003.

Allcott, Hunt. 2011b. Social norms and energy conservation. Journal of Public Economics 95(9-10) 1082-1095. doi:10.1016/j.jpubeco.2011.03.003. URL http://dx.doi.org/10. $1016 / j \cdot j$ pubeco 2011.03 .003$.

Baldini, Mattia, Henrik Klinge Jacobsen. 2016. Optimal trade-offs between Energy Efficiency improvements and additional Renewable Energy supply : A review of international experiences URL http://ieeexplore.ieee.org/document/7521245/.

Ball, Michael, Martin Wietschel, Otto Rentz. 2007. Integration of a hydrogen economy into the German energy system: an optimising modelling approach. International Journal of Hydrogen Energy 32(10-11) 1355-1368. doi:10.1016/j.ijhydene.2006.10.016.

Balmorel. 2015. Balmorel: energy system model. URL http://www.eabalmorel.dk/.

Bartiaux, Françoise, Kirsten Gram-Hanssen. 2005. Socio-political factors influencing household electricity consumption : A comparison between Denmark and Belgium. ECEE 2005 Summer Study 1313-1325.

Batih, Hakimul, Chumnong Sorapipatana. 2016. Characteristics of urban households' electrical energy consumption in Indonesia and its saving potentials. Renewable and Sustainable Energy Reviews 57 1160-1173. doi:10.1016/j.rser.2015.12.132. URL http: //dx.doi.org/10.1016/j.rser.2015.12.132.

Breum, Henrik. 2015. The danish energy model. Tech. rep., København. URL https: //ens.dk/en/our-responsibilities/global-cooperation/danish-energy-model.

Broman Toft, Madeleine, Geertje Schuitema, John Thøgersen. 2014. The importance of framing for consumer acceptance of the Smart Grid: A comparative study of Denmark, Norway and Switzerland. Energy Research and Social Science 3(C) 113-123. doi: 10.1016/j.erss.2014.07.010. URL http://dx.doi.org/10.1016/j.erss.2014.07.010.

Bulu, Abdulkadir, Nurgün Topalli. 2011. Energy Efficiency and Rebound Effect: Does Energy Efficiency Save Energy? Energy and Power Engineering 03(03) 355-360. doi:10.4236/ epe.2011.33045. 
Bunch, David S., Kalai Ramea, Sonia Yeh, Christopher Yang. 2015. Incorporating Behavioral Effects from Vehicle Choice Models into Bottom-Up Energy Sector Models (July). doi: 10.13140/RG.2.1.2892.1447.

Cabeza, Luisa F, Diana Urge-Vorsatz, Michael A Mcneil, Camila Barreneche, Susana Serrano. 2014. Investigating greenhouse challenge from growing trends of electricity consumption through home appliances in buildings. Renewable and Sustainable Energy Reviews 36 188-193. doi:10.1016/j.rser.2014.04.053. URL http://dx.doi.org/10.1016/j.rser. 2014.04 .053$.

Carnall, Michael, Larry Dale, Alex Lekov. 2015. The economic effect of efficiency programs on energy consumers and producers. Energy Efficiency 647-662doi:10.1007/ s12053-015-9390-y. URL http://dx.doi.org/10.1007/s12053-015-9390-y.

Connolly, D., H. Lund, B. V. Mathiesen, S. Werner, B. Möller, U. Persson, T. Boermans, D. Trier, P. A. Østergaard, S. Nielsen. 2014. Heat roadmap Europe: Combining district heating with heat savings to decarbonise the EU energy system. Energy Policy 65 475-489. doi:10.1016/j.enpol.2013.10.035. URL http://dx.doi.org/10.1016/j. enpol.2013.10.035.

COOPER, MARK. 2011. Public Attitudes Toward Energy Effiency and Appliance Efficiency Standards :. Consumer Federation of America .

Danish Energy Agency. 2014. Denmark's National Energy Efficiency Action Plan (NEEAP). Tech. Rep. April.

Danish Energy Agency. 2016a. Energy Efficiency trends and policies in Denmark. Tech. Rep. January, Copenhagen. URL http://www.odyssee-mure.eu/publications/ national-reports/energy-efficiency-denmark.pdf.

Danish Energy Agency. 2016b. Forudsætninger for samfundsøkonomiske analyser på energiområdet (Guidelines for socio-economic analysis in the field of energy; in Danish). Tech. rep., Copenhagen.

Danish Ministry of Energy Utilities and Climate. 2013. Smart meters in all the households (Smarte elmålere i alle hjem: in Danish). URL http://www.efkm.dk/nyheder/ smarte-elmaalere-hjem.

Danish Ministry of Energy Utilities and Climate. 2014. Bekendtgørelse om fjernaflæste elmålere og måling af elektricitet i. URL https://www.retsinformation.dk/ pdfPrint.aspx?id=160434.

Danmark NationalBank. 2016. Official Interest Rates. URL http://www .nationalbanken. $\mathrm{dk} /$ en/marketinfo/official___\}interestrates/Pages/default.aspx.

Davis, Lucas W., Gilbert E. Metcalf. 2014. Does Better Information Lead to Better Choices? Evidence from Energy-Efficiency Labels. doi:10.3386/w20720. URL http://www . nber . org/papers/w20720. 
Energitilsynet. 2016. ELPRIS.DK. URL http://elpris.dk/\{\#\}/.

Enkvist, Per-Anders, Tomas Nauclér, Jerker Rosander. 2007. A cost curve for greenhouse gas reduction. McKinsey Quarterly (1) 34-45. URL http: //ezproxy.lib.utexas.edu/login?url=http://search.ebscohost.com/login. aspx?direct $=\operatorname{true}\{\&\} \mathrm{db}=\mathrm{bth}\{\&\} \mathrm{AN}=24215973\{\&\}$ site=ehost-live.

European Commission. 2010. Energy 2020. Tech. rep. doi:10.2833/78930.

European Commission. 2012. Green Paper - A 2030 framework for climate and energy policies

Evora, Jose, Enrique Kremers, Susana Morales, Mario Hernandez, Jose Juan Hernandez, Pablo Viejo. 2011. Agent-Based Modelling of Electrical Load at Household Level. ECAL 2011: CoSMoS - Proceedings of the 2011 Workshop on Complex Systems Modelling and Simulation 12.

Farinelli, Ugo, Thomas B. Johansson, Kes McCormick, Luis Mundaca, Vlasis Oikonomou, Mattias Örtenvik, Martin Patel, Federico Santi. 2005. White and Green: Comparison of market-based instruments to promote energy efficiency. Journal of Cleaner Production doi:10.1016/j.jclepro.2004.12.013.

Faruqui, Ahmad, Dan Harris, Ryan Hledik. 2010. Unlocking the 53 billion savings from smart meters in the EU: How increasing the adoption of dynamic tariffs could make or break the EU's smart grid investment. Energy Policy 38(10) 6222-6231. doi:10.1016/j.enpol. 2010.06.010. URL http://dx.doi.org/10.1016/j.enpol.2010.06.010.

Galarraga, Ibon, Luis M Abadie, Alberto Ansuategi. 2013. Efficiency, effectiveness and implementation feasibility of energy efficiency rebates : The Renove plan in Spain doi:10.1016/j.eneco.2013.09.012.

Galvin, Ray. 2010. Thermal upgrades of existing homes in Germany: The building code, subsidies, and economic efficiency. Energy and Buildings doi:10.1016/j.enbuild.2009.12. 004.

Hansen, Kenneth, David Connolly, Henrik Lund, David Drysdale, Jakob Zinck Thellufsen. 2016. Heat Roadmap Europe: Identifying the balance between saving heat and supplying heat. Energy doi:10.1016/j.energy.2016.06.033. URL http://dx.doi.org/10.1016/j . energy.2016.06.033.

Hausman, Jerry A. 1979. Individual Discount Rates and the Purchase and Utilization of Energy-Using Durables. The Bell Journal of Economics 10:1 33-54. doi:10.2307/ 3003318.

Houde, Sébastien. 2014. How Consumers Respond to Environmental Certification and the Value of Energy Information. National Bureau of Economic Research Working Paper Series No. 20019(August). doi:10.3386/w20019. URL http://www.nber.org/papers/ w20019\$delimiter"067A848\$nhttp://www.nber.org/papers/w20019.pdf. 
IEA. 2016. Nordic Energy Technology Perspectives 2016. Energy Technology Policy Division (April) 650. doi:10.1787/9789264257665-en. URL http://www.iea.org/techno/etp/ index.asp.

Ipcc. 2007. Mitigation of climate change: Contribution of working group III to the fourth assessment report of the Intergovernmental Panel on Climate Change.

Jensen, Stine Grenaa, Peter Meibom. 2008. Investments in liberalised power markets. Gas turbine investment opportunities in the Nordic power system. International Journal of Electrical Power and Energy Systems 30(2) 113-124. doi:10.1016/j.ijepes.2007.06.029.

Karlsson, Kenneth, Peter Meibom. 2008. Optimal investment paths for future renewable based energy systems-Using the optimisation model Balmorel. International Journal of Hydrogen Energy 33(7) 1777-1787. doi:10.1016/j.ijhydene.2008.01.031.

Katz, Jonas. 2014. Linking meters and markets: Roles and incentives to support a flexible demand side. Utilities Policy 31 74-84. doi:10.1016/j.jup.2014.08.003. URL http: //dx.doi.org/10.1016/j.jup.2014.08.003.

Katz, Jonas, Frits Møller Andersen, Poul Erik Morthorst. 2016. Load-shift incentives for household demand response: Evaluation of hourly dynamic pricing and rebate schemes in a wind-based electricity system. Energy doi:10.1016/j.energy.2016.07.084. URL http: //dx.doi.org/10.1016/j.energy.2016.07.084.

Khazzoom, J. Daniel. 1980. Economic Implications of Mandated Efficiency in Standards for Household Appliances. The Energy Journal Volume 1(Number 4) 21-40.

Klinge Jacobsen, Henrik, Nina Juul. 2015. Demand-side management: electricity savings in Danish households reduce load variation, capacity requirements, and associated emissions @ DTU International Energy Report 2015 : Energy systems integration for the transition to non-fossil energy systems. Tech. rep., Technical University of Denmark DTU.

Krishnamurti, Tamar, Daniel Schwartz, Alexander Davis, Baruch Fischhoff, Wändi Bruine de Bruin, Lester Lave, Jack Wang. 2012. Preparing for smart grid technologies: A behavioral decision research approach to understanding consumer expectations about smart meters. Energy Policy 41 790-797. doi:10.1016/j.enpol.2011.11.047.

Lefebvre, S., C. Desbiens. 2002. Residential load modeling for predicting distribution transformer load behavior, feeder load and cold load pickup. International Journal of Electrical Power and Energy Systems 24(4) 285-293. doi:10.1016/S0142-0615(01)00040-0.

López-Peña, Álvaro, Ignacio Pérez-Arriaga, Pedro Linares. 2012. Renewables vs. energy efficiency: The cost of carbon emissions reduction in Spain. Energy Policy doi: 10.1016/j.enpol.2012.08.006.

Mills, Bradford, Joachim Schleich. 2010. What's driving energy efficient appliance label awareness and purchase propensity? Energy Policy 38(2) 814-825. doi:10.1016/j.enpol.2009. 10.028 . 
Mizobuchi, Kenichi, Kenji Takeuchi. 2016. Replacement or additional purchase: The impact of energy-efficient appliances on household electricity saving under public pressures. Energy Policy 93 137-148. doi:10.1016/j.enpol.2016.03.001. URL http://dx.doi.org/10. 1016/j.enpol.2016.03.001.

Münster, M., P. Meibom. 2010. Long-term affected energy production of waste to energy technologies identified by use of energy system analysis. Waste Management 30(12) 2510-2519. doi:10.1016/j.wasman.2010.04.015.

Münster, Marie. 2009. Energy System Analysis of Waste-to-Energy technologies. Energy (June). doi:978-87-91830-36-5.

Münster, Marie, Poul Erik Morthorst, Helge V. Larsen, Lars Bregnbæk, Jesper Werling, Hans Henrik Lindboe, Hans Ravn. 2012. The role of district heating in the future Danish energy system. Energy 48(1) 47-55. doi:10.1016/j.energy.2012.06.011.

Murray, Anthony G., Bradford F. Mills. 2011. Read the label! Energy Star appliance label awareness and uptake among U.S. consumers. Energy Economics 33(6) 11031110. doi:10.1016/j.eneco.2011.04.013. URL http://dx.doi.org/10.1016/j.eneco. 2011.04 .013$.

Nässén, Jonas, John Holmberg. 2009. Quantifying the rebound effects of energy efficiency improvements and energy conserving behaviour in Sweden. Energy Efficiency 2(3) 221231. doi:10.1007/s12053-009-9046-x.

Newell, Richard G., Juha V. Siikamäki. 2013. Nudging Energy Efficiency Behaviour: The role of information labels. doi:10.3386/w19224. URL http://www.nber.org/papers/ w19224.pdf.

NordPoolSpot. 2016. Nord Pool Spot. URL http://www.nordpoolspot.com/ historical-market-data/.

Oilprice.com. 2016. Crude Oil Prices Today. URL http://oilprice.com/.

Parikh, Kirit S., Jyoti K. Parikh. 2016. Realizing potential savings of energy and emissions from efficient household appliances in India. Energy Policy 97 102-111. doi:10.1016/j. enpol.2016.07.005. URL http://dx.doi.org/10.1016/j.enpol.2016.07.005.

Reuters, Thomson. 2016. Point Carbon Energy Research. URL http://financial. thomsonreuters.com/en/resources/articles/point-carbon.html.

Rodríguez Fernández, M., I. González Alonso, E. Zalama Casanova. 2015. Online identification of appliances from power consumption data collected by smart meters. Pattern Analysis and Applications (September) 463-473. doi:10.1007/s10044-015-0487-x. URL http: //link. springer.com/10.1007/s10044-015-0487-x.

Schaffrin, André, Nadine Reibling. 2015. Household energy and climate mitigation policies: Investigating energy practices in the housing sector. Energy Policy 77 1-10. doi:10. 1016/j.enpol.2014.12.002. URL http://dx.doi.org/10.1016/j.enpol.2014.12.002. 
Shen, Junyi, Tatsuyoshi Saijo. 2009. Does an energy efficiency label alter consumers' purchasing decisions? A latent class approach based on a stated choice experiment in Shanghai. Journal of Environmental Management 90(11) 3561-3573. doi:10.1016/j.jenvman.2009. 06.010. URL http://dx.doi.org/10.1016/j.jenvman.2009.06.010.

Shrestha, Ram M., C. O P Marpaung. 2006. Integrated resource planning in the power sector and economy-wide changes in environmental emissions. Energy Policy doi:10.1016/j. enpol.2005.08.017.

Statistics Denmark. 2016. Statistics Denmark. URL https://www.dst.dk/en.

Swan, Lukas G., V. Ismet Ugursal. 2009. Modeling of end-use energy consumption in the residential sector: A review of modeling techniques. Renewable and Sustainable Energy Reviews 13(8) 1819-1835. doi:10.1016/j.rser.2008.09.033.

UserTEC. 2016. UserTEC User Practices, Technologies and Residential Energy Consumption. doi:10.1017/CBO9781107415324.004. URL http://sbi.dk/usertec.

Wada, Kenichi, Keigo Akimoto, Fuminori Sano, Junichiro Oda, Takashi Homma. 2012. Energy efficiency opportunities in the residential sector and their feasibility. Energy 48(1) 5-10. doi:10.1016/j.energy.2012.01.046. URL http://dx.doi.org/10.1016/j . energy . 2012. 01.046.

Ward, David O., Christopher D. Clark, Kimberly L. Jensen, Steven T. Yen, Clifford S. Russell. 2011. Factors influencing willingness-to-pay for the ENERGY STAR® label. Energy Policy 39(3) 1450-1458. doi:10.1016/j.enpol.2010.12.017. URL http://dx.doi.org/ $10.1016 / j$.enpol.2010.12.017.

Xie, Qing, Hongbing Ouyang, Xiang Gao. 2016. Estimation of electricity demand in the residential buildings of China based on household survey data. International Journal of Hydrogen Energy 41(35) 15879-15886. doi:10.1016/j.ijhydene.2016.03.152. URL http: //dx.doi.org/10.1016/j.ijhydene.2016.03.152.

Zvingilaite, Erika. 2013. Modelling energy savings in the Danish building sector combined with internalisation of health related externalities in a heat and power system optimisation model. Energy Policy 55 57-72. doi:10.1016/j.enpol.2012.09.056. URL http://dx.doi. org/10.1016/j.enpol.2012.09.056.

Zvingilaite, Erika, Olexandr Balyk. 2014. Heat savings in buildings in a 100\% renewable heat and power system in Denmark with different shares of district heating. Energy and Buildings 82 173-186. doi:10.1016/j.enbuild.2014.06.046. URL http://dx.doi.org/ $10.1016 / j$.enbuild.2014.06.046.

Zvingilaite, Erika, Henrik Klinge Jacobsen. 2015. Heat savings and heat generation technologies: Modelling of residential investment behaviour with local health costs. Energy Policy 77 31-45. doi:10.1016/j.enpol.2014.11.032. URL http://dx.doi.org/10.1016/ j.enpol.2014.11.032. 